\title{
Environmentally benign process for benzylation of toluene to mono-benzylated toluene over highly active and stable hierarchical zeolite catalyst
}

\author{
Kakasaheb Y. Nandiwale • Pratika Thakur • \\ Vijay V. Bokade
}

Received: 19 September 2014/ Accepted: 26 December 2014/Published online: 23 January 2015

(C) The Author(s) 2015. This article is published with open access at Springerlink.com

\begin{abstract}
The liquid-phase benzylation of toluene with a benzylating agent like benzyl chloride (BC) is an important process for the production of mono-benzylated toluene (MBT), which is an industrially important compound used in pharmaceutical intermediates, fragrances, monomers for polycarbonate resins, heat-transfer fluids, aromatic solvents and fine chemicals. Selective synthesis of MBT by benzylation of toluene with BC over hierarchical micro-mesoporous-H-ZSM-5 (modified zeolite) catalyst was systematically studied for the first time. Hierarchical micro-mesoporous composites of H-ZSM-5 were obtained by treating parent H-ZSM-5 with different alkali (aq. $\mathrm{NaOH}$ ) concentration. The synthesized catalysts were characterized by powder X-ray diffraction (XRD), BET surface area, TPAD, etc. The $100 \%$ BC conversion with $100 \%$ MBT selectivity was obtained over Hier-HZ-5 78 (Hierarchical H-ZSM-5) at lower molar ratio (toluene:BC) of 4:1 than 10:1 molar ratio reported, so far. The invented catalyst was also observed to be reusable for six catalytic cycles (one fresh and five recycles). The detailed optimization of process parameters such as molar ratio, catalyst loading and reaction time and temperature is also discussed.
\end{abstract}

Keywords Toluene - Benzyl chloride - Benzylation · Mono-benzylated toluene $\cdot$ Hier-HZ-5 78

K. Y. Nandiwale $\cdot$ P. Thakur · V. V. Bokade $(\bowtie)$

Catalysis and Inorganic Chemistry Division, CSIR - National

Chemical Laboratory, Pune 411008, India

e-mail: vv.bokade@ncl.res.in

\section{Introduction}

Friedel-Crafts alkylation is an important means of attaching alkyl chains to aromatic rings and hence is a key reaction in organic chemistry $[1,2]$. The liquid-phase benzylation of aromatics, namely toluene, benzene, xylene, etc., using benzylating agent like benzyl chloride (BC) or benzyl alcohol is an important process for the production of mono-benzylated toluene (MBT), benzyltoluene, benzoic acid, substituted diphenyl methane, etc., especially selective synthesis of MBT, which is industrially important compounds used as pharmaceutical intermediates, fragrances, monomers for polycarbonate resins, heat-transfer fluids, aromatic solvents and fine chemicals [1-6].

The catalysts used in these reactions are often homogeneous, such as $\mathrm{AlCl}_{3}, \mathrm{FeCl}_{3}, \mathrm{HF}, \mathrm{H}_{2} \mathrm{SO}_{4}$ and $\mathrm{BF}_{3}$ [3, 4]. Although, homogeneous catalysts are readily available and inexpensive, these catalysts pose numerous problems, which include potential dangers in handling, toxicity, difficulty in separation and recovery, disposal problems due to large amounts of acidic effluent and corrosive nature [5-9]. These drawbacks become a major disadvantage in terms of environmental concerns, emphasizing the need to develop an alternative to the conventional, homogeneous acid catalyst. The fundamental concept is to identify new, stable, and recyclable catalysts as replacements for the conventional liquid acids, leading to development of environmentally safe industrial processes. Thus, there has been much interest to replace homogeneous catalysts with heterogeneous solid acid catalysts, having advantages mainly because of easy catalyst recovery, reusability, and work-up of reaction products [5-9]. During the past decade, much attention has been paid to the replacement of homogeneous catalysts by solid acid catalysts. Among these solid catalysts, the zeolite catalysts are outstanding due to their 
shape-selectivity, thermostability, and the possibility of regeneration of the deactivated catalysts [5-10]. Hence, the catalytic performances of different modified zeolites such as AlSBA-15 [5], HPA/TS-1 [6], Fe-SBA-15 [7], nanocrystalline sulfated titania [8] and Fe-containing HMCM48 [9], etc., have been extensively evaluated for benzylation of toluene with $\mathrm{BC}$.

However, to the best of our knowledge, hierarchical micro-mesoporous composite of H-ZSM-5 obtained by desilication as catalysts for catalytic benzylation of toluene with $\mathrm{BC}$ has not been reported so far. In this study, we reported the preparation, characterization and catalysis of hierarchical micro-mesoporous composite H-ZSM-5 in the benzylation of toluene with $\mathrm{BC}$ for the first time. The detail optimization of process parameters, catalyst reusability along with the merits of the present study is also discussed.

\section{Experimental}

Catalyst synthesis and characterization

The reported procedure was used to synthesize the parent H-ZSM-5 with Si/Al ratio of 37 [11]. The hierarchical micro-mesopore composite samples, Hier-HZ-590, HierHZ- $5_{78}$, and Hier-HZ-568 (the subscripts indicate percentage relative crystallinity of catalyst sample), were obtained by treatment of H-ZSM-5 (parent) with $0.4,0.8$, and $1.2 \mathrm{M}$ aq. $\mathrm{NaOH}$ in a proportion of $30 \mathrm{~mL} \mathrm{~g}^{-1}(\mathrm{v} / \mathrm{w})$ for $30 \mathrm{~min}$ at $338 \mathrm{~K}$, respectively. The zeolite samples were transformed into ammonium forms by threefold ion exchange with aq. $0.1 \mathrm{M}$ ammonium nitrate (with a proportion of $10 \mathrm{~mL} \mathrm{~g}^{-1}$ of product for $5 \mathrm{~h}$ ) without calcinations in between ion-exchange procedures. Finally, samples were transformed into the hydrogen forms to restore the Brönsted acid sites by calcinations in air at $823 \mathrm{~K}$ for $5 \mathrm{~h}$. The phase purity and crystallinity were determined by powder X-ray diffraction (XRD), P-Analytical PXRD system, Model X-Pert PRO-1712 (Fig. 1a). Low temperature $(77 \mathrm{~K})$ nitrogen adsorption and desorption isotherms of H-ZSM-5 and Hier-HZ- $5_{78}$ catalysts were obtained using SA 3100 analyser (Beckman Coulter, CA, USA) (Fig. 1b). The specific surface area and pore diameter of catalysts were calculated using Brunauer-Emmett-Teller (BET) method and Barrett-Joyner-Halenda (BJH) model, respectively (Table 1). The total acidity of all samples was obtained with temperature programmed ammonia desorption (TPAD) by Micrometrics AutoChem (2910, USA) coupled with a thermal conductivity detector (Table 1). Benzyl chloride ( $>99 \%)$ and toluene $(>99 \%)$ were procured from S D Fine-Chem Ltd. Mumbai (India). All the reagents were of analytical grade and used without further purification.
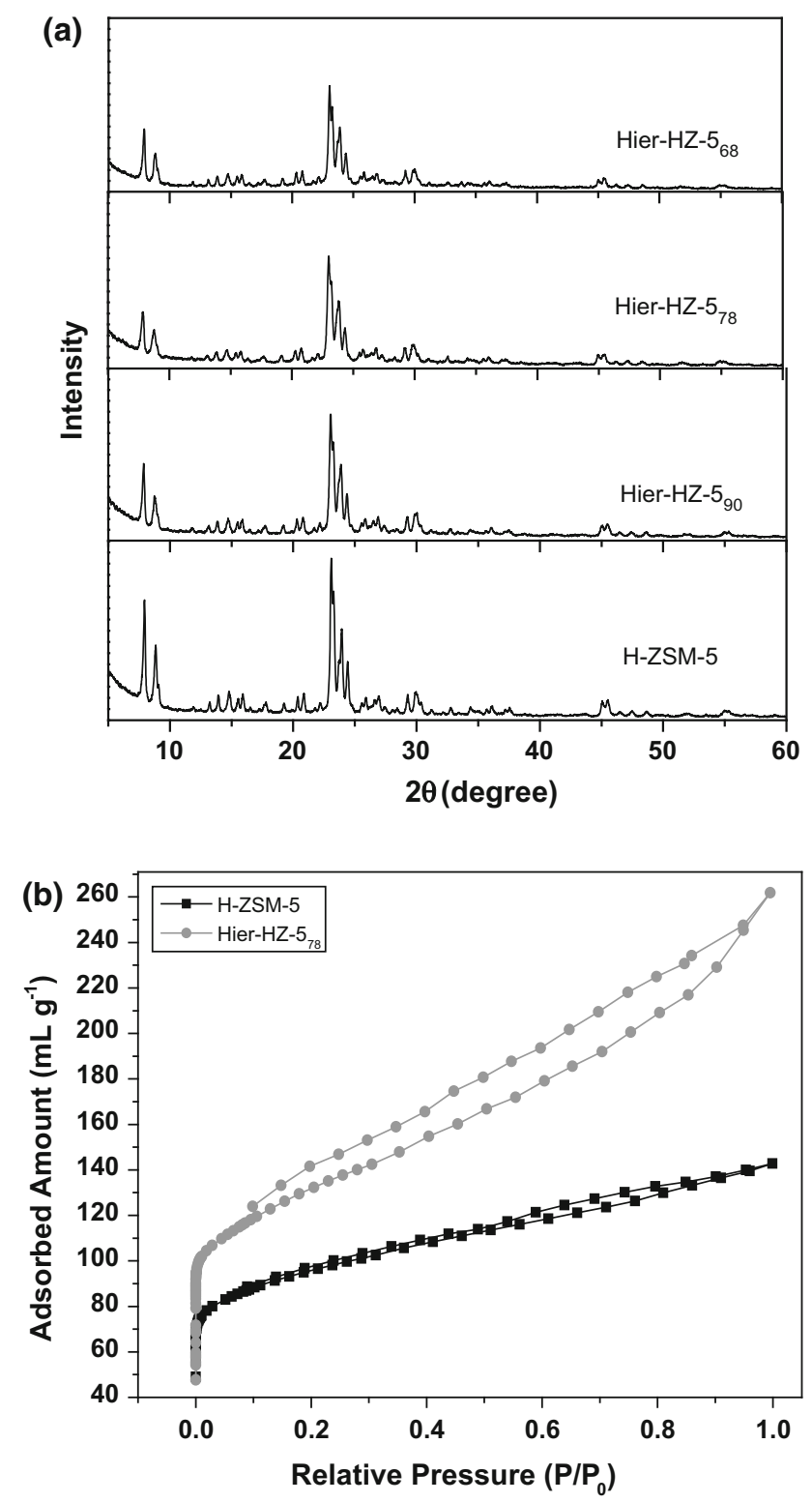

Fig. 1 Characterizations of H-ZSM-5 (parent) and its hierarchical micro-mesopore composites: a Powder X-ray diffraction (XRD) patterns and $\mathbf{b} \mathrm{N}_{2}$ adsorption-desorption isotherms

\section{Catalytic evaluation and analysis}

The synthesized catalysts were evaluated in benzylation of toluene with BC, which was carried out in a two-necked glass round bottom flask of $50 \mathrm{~mL}$ capacity equipped with a reflux condenser, a thermometer and a magnetic stirrer. The temperature was maintained within an accuracy of $\pm 0.5 \mathrm{~K}$ by an electric-heated thermostatic oil bath. The flask was charged with toluene and $\mathrm{BC}$, both weighted sequentially with molar feed ratio of $4: 1$ with $22.33 \mathrm{~g}(\mathrm{w} / \mathrm{v})$

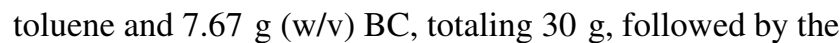
addition of the catalyst $0.77 \mathrm{~g}(\mathrm{w} / \mathrm{w})(10 \mathrm{wt}$. \% of $\mathrm{BC}$ limiting reactant). Then, the system was heated up to 
Table 1 Physico-chemical properties of catalysts

\begin{tabular}{llllllll}
\hline Catalyst & $\begin{array}{l}\text { Total acidity } \\
\left(\mu \mathrm{mol} \mathrm{g}^{-1}\right)\end{array}$ & $\begin{array}{l}\text { BET surface } \\
\text { area }\left(\mathrm{m}^{2} \mathrm{~g}^{-1}\right)\end{array}$ & $\begin{array}{l}\text { Pore } \\
\text { diameter }(\AA)\end{array}$ & \multicolumn{2}{l}{ Volume $\left(\mathrm{cm}^{3} \mathrm{~g}^{-1}\right)$} \\
\cline { 5 - 7 } & & & & Micro & Meso & Total \\
\hline H-ZSM-5 & 511 & 300.8 & - & - & - & - \\
Hier-HZ-5 & 775 & 430.1 & 30.09 & 0.199 & 0.136 & 0.335 \\
Hier-HZ-5 & 814 & 438.9 & 30.68 & 0.283 & 0.139 & 0.422 \\
Hier-HZ-5 & 639 & 442.5 & 30.18 & 0.313 & 0.140 & 0.453 \\
\hline
\end{tabular}

required temperature (373-393 K), the reaction was carried out for $0.5-4 \mathrm{~h}$ and finally the product was collected after removing the catalyst. The liquid reaction products such as MBT and dibenzylated toluene (DBT) were analyzed by using gas chromatography (GC) Chemito GC-1000, capillary column, BP-5 (50 m length and $0.3 \mathrm{~mm}$ width) with nitrogen as a carrier gas and flame ignition detector (FID) in programmable temperature range $313-473 \mathrm{~K}$.

$\mathrm{BC}$ conversion and MBT selectivity were calculated from following formulae:

$\mathrm{BC}$ conversion $(\%)$

$=[(\mathrm{BC}$ in feed $-\mathrm{BC}$ in product $) /(\mathrm{BC}$ in feed $)] \times 100$

MBT selectivity (\%)

$=[(\mathrm{MBT}$ in product $/$ Total MBT and DBT in product $)]$ $\times 100$

\section{Results and discussion}

\section{Catalyst characterization}

The powder X-ray diffraction (XRD) patterns of all H-ZSM-5 (parent) and hierarchical micro-mesoporous composites obtained by treatment of different aq. $\mathrm{NaOH}$ concentrations are shown in Fig. 1a. The relative crystallinities of hierarchical catalyst samples, considering parent H-ZSM-5 as $100 \%$ crystalline are shown as subscripts. XRD pattern of H-ZSM-5 (parent) revealed fully (100\%) crystalline MFI phase. The catalysts exhibited the trend of relative crystallinity as H-ZSM-5 $(100 \%)>0.4 \mathrm{M}$ aq. $\mathrm{NaOH}\left(\right.$ Hier-HZ-5 $5_{90}>0.8$ aq. $\mathrm{NaOH}\left(\right.$ Hier-HZ- $\left.5_{78}\right)>1.2$ aq. $\mathrm{NaOH}$ (Hier-HZ-568). The $\mathrm{NaOH}$-treated samples exhibited decrease in the intensity of characteristic peaks of MFI phase, which is ascribed to removal of $\mathrm{Si}$ atoms from zeolite framework, but the basic fingerprints of MFI phase are preserved in all the samples.

$\mathrm{N}_{2}$ adsorption-desorption isotherms of H-ZSM-5 and Hier-HZ-5 $5_{78}$ are shown in Fig. 1b. H-ZSM-5 exhibited type I isotherm which is of typical microporous material. HierHZ- $5_{78}$ indicated both type I and type IV isotherms, which represent presence of both micro and mesoporosity in the aq. $\mathrm{NaOH}$-treated catalyst sample [10].

The physico-chemical properties of all catalyst samples are presented in Table 1. The alkali treatment tends to removal of silicon atoms with accompanying oxygen atoms, which in turn resulted in generation of mesopore, increase in BET surface area and acidity [10]. The use of $\mathrm{NaOH}$ with concentration $>0.8 \mathrm{M}$ may remove $\mathrm{Al}$ atom along with $\mathrm{Si}$ atom from zeolite framework, which might be contributing to the decrease in an acid sites (Table 1).

Catalytic performance of H-ZSM-5 and its hierarchical composites

The catalytic performance of Blank (without catalyst), H-ZSM-5 (parent) and its hierarchical micro-mesopore composites (Hier-HZ-5) was evaluated for toluene benzylation with $\mathrm{BC}$ at an identical set of process parameters (Fig. 2). All the experiments were performed in duplicate and have $\pm 2 \%$ error. Friedel-Crafts benzylation of toluene with BC leads to formation of MBT along with DBT (Scheme 1). It can be seen from Fig. 2, in the absence of a

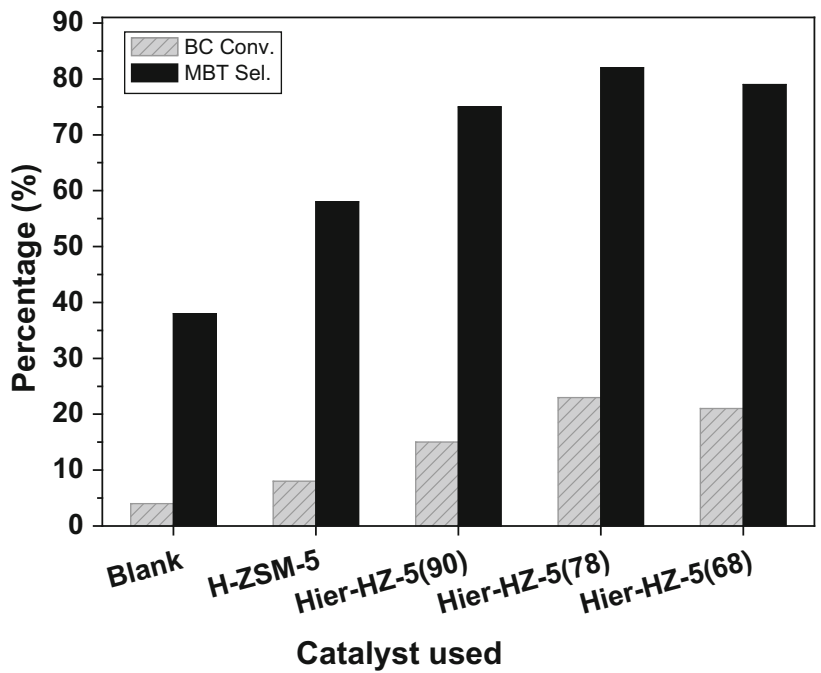

Fig. 2 Benzylation of toluene with BC over Blank, H-ZSM-5 and Hierarchical-HZ-5 (reaction conditions: molar ratio (toluene:BC) of $2: 1$, catalyst loading: $10 \%$, reaction temperature: $383 \mathrm{~K}$, reaction time: $2 \mathrm{~h}$, speed of agitation: $400 \mathrm{rpm}$ and average particle size of catalyst: $82.5 \mu \mathrm{m}$ ) 
<smiles>Cc1ccccc1</smiles>

Tolune<smiles>ClCc1ccccc1</smiles>

Benzyl chloride

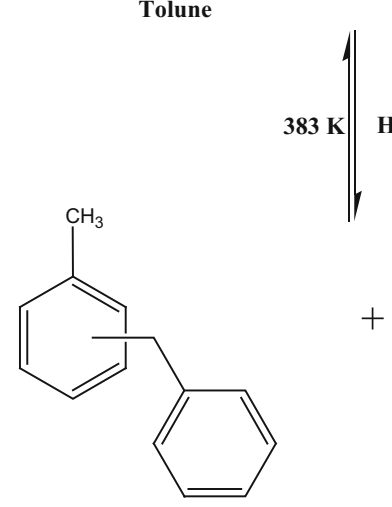

Mono-Benzylated Tolune (MBT)

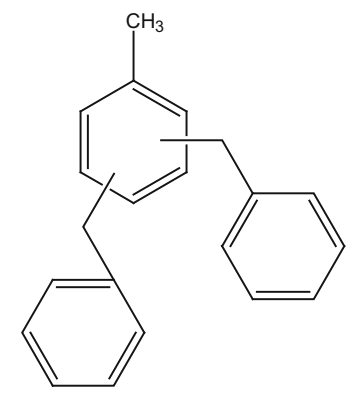

Di-Benzylated Tolune (DBT)
Scheme 1 Reaction pathway for benzylation of toluene with BC

catalyst (Blank), MBT was formed but at lower BC conversion $(4 \%)$. The overall trend of $\mathrm{BC}$ conversion was H-ZSM-5 $(8 \%)<$ Hier-HZ-5 $90 \quad(15 \%)<$ Hier-HZ-5 $_{68}$ $(21 \%)<$ Hier-HZ-5 78 (23\%). The lower activity of parent H-ZSM-5 may be due to the less acidity, and micropores of H-ZSM-5 may exhibit diffusional resistances towards bulkier molecules like MBT. All the hierarchical micro-mesopore composites showed higher BC conversion and MBT selectivity than parent H-ZSM-5. The hierarchical micro-mesopore composite sample, Hier-HZ$5_{78}$ exhibited highest BC conversion (23\%) and MBT selectivity ( $82 \%$ ) amongst the studied catalysts. This can be attributed to enhancement in surface area, total acidity along with pore volume of Hier-HZ-5 78 (Table 1). Although, Hier-HZ-568 catalyst bears higher surface area and pore volume (Table 1) than Hier-HZ-5 78 , it exhibited lower BC conversion (21\%) and MBT selectivity (79\%) than Hier-HZ-5 78 (Fig. 2). This may be due to drop in total acidity by dealumination at excess $\mathrm{NaOH}$ concentration (1.2 M) (Table 1). Hence, Hier-HZ-5 78 was selected as a potential catalyst for benzylation of toluene with $\mathrm{BC}$ and further optimization of process parameters were performed in view to maximize $\mathrm{BC}$ conversion and MBT selectivity. All the experiments were done in kinetically controlled regime excluding internal and external mass transfer resistances, by using average catalyst particle size of $82.5 \mu \mathrm{m}$ and speed of agitation of $400 \mathrm{rpm}$ [12].
Optimization of process parameters

\section{Effect of catalyst loading}

To obtain the optimum loading of Hier-HZ-5 78 catalyst for toluene benzylation, the catalyst loading was varied from 5 to $20 \%$ (wt. \% of BC). The catalyst loading was varied with respect to wt. \% of limiting reactant (BC). The reactions were performed at $30 \mathrm{~g}$ scale with toluene to $\mathrm{BC}$ molar ratio of $4: 1[22.33 \mathrm{~g}(\mathrm{w} / \mathrm{v})$ toluene and $7.67 \mathrm{~g}(\mathrm{w} / \mathrm{v})$ $\mathrm{BC}$ ] and with various amounts of catalyst (wt. \% of BC) $5 \%(0.38 \mathrm{~g}), 10 \%(0.77 \mathrm{~g}), 15 \%(1.15 \mathrm{~g})$ and $20 \%$ $(1.53 \mathrm{~g})$. As illustrated in Fig. 3, with the increase in loading of Hier-HZ- $5_{78}$ catalyst from 5 to $10 \%$, the BC conversion and MBT selectivity increased from 76 to 90 and 88 to $97 \%$, respectively, because of the increase in total number of acid sites available for the reaction. On further increase in catalyst loading from 10 to $20 \%$, there was no change in BC conversion and MBT selectivity. The $\mathrm{BC}$ conversion was observed to be varied with change in catalyst amount, revealing that the reaction proceeds through pure heterogeneous mechanism. Thus, Hier-HZ$5_{78}$ catalyst loading of $10 \%$ with $90 \%$ BC conversion and $97 \%$ MBT selectivity was chosen as an optimum and used in further experiments.

\section{Effect of molar ratio}

One of the most important parameters in Friedel-Crafts reactions is the dilution of substrate. To determine the optimum solvent/reactant ratio (toluene:BC) needed for Friedel-Crafts benzylation reaction, the compositions with different ratio of the solvent (toluene) and reactant (BC)

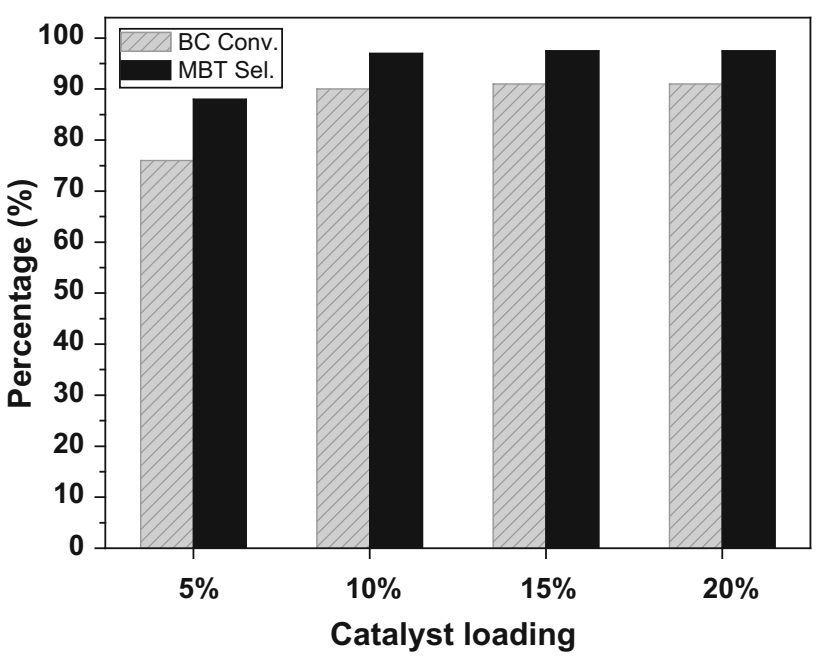

Fig. 3 Effect of catalyst loading on toluene benzylation with BC over Hier-HZ-5 ${ }_{78}$ (reaction conditions: molar ratio (toluene:BC) of 4:1, reaction temperature: $383 \mathrm{~K}$ and reaction time: $2 \mathrm{~h}$ ) 
were studied $(1: 1,2: 1,3: 1,4: 1$ and 5:1). The results obtained from the reactions are represented in Fig. 4. With increase in molar ratio from 1:1 to 4:1, the BC conversion and MBT selectivity were found to be increased linearly from 12 to 90 and 67 to $97 \%$, respectively. Thereafter, with further increase in molar ratio from $4: 1$ to $5: 1$, there was no significant increase in $\mathrm{BC}$ conversion and $\mathrm{MBT}$ selectivity. At lower toluene to $\mathrm{BC}$ ratios, the amount of polyalkylation was negligible, while it considerably increased at higher molar ratios. Thus, when the concentration of toluene was increased, the carbocation had a higher probability of attacking the toluene, which leads to the formation of higher MBT. The results revealed that benzylation is favored with a lower concentration of benzylating agent (BC). In addition, at higher concentration of benzylating agent, the alkylated products may enhance the poisoning effect by adsorbing strongly on the catalyst surface [8]. This leads to restriction of further adsorption of the $\mathrm{BC}$ (reactant) molecules and in turn reduces the $\mathrm{BC}$ conversion. On the contrary, at high toluene to $\mathrm{BC}$ molar ratio, this inhibition would be less significant, facilitating desorption of the products formed at catalytic sites easily. Thus, the effect of molar feed ratio is dependent of catalyst wt. ratio. From the results obtained, the best solvent/reactant molar ratio was 4:1 (toluene:BC) (Fig. 4).

\section{Effect of reaction time and temperature}

In view to obtain the optimum process parameters, the benzylation reactions of toluene with $\mathrm{BC}$ over Hier-HZ-5 78 were performed at different times $(0.5-4 \mathrm{~h})$ and temperatures (373-393 K). As shown in Fig. 5, with the increase in time, the steady increase in $\mathrm{BC}$ conversion and MBT selectivity was observed. Complete $\mathrm{BC}$ conversion

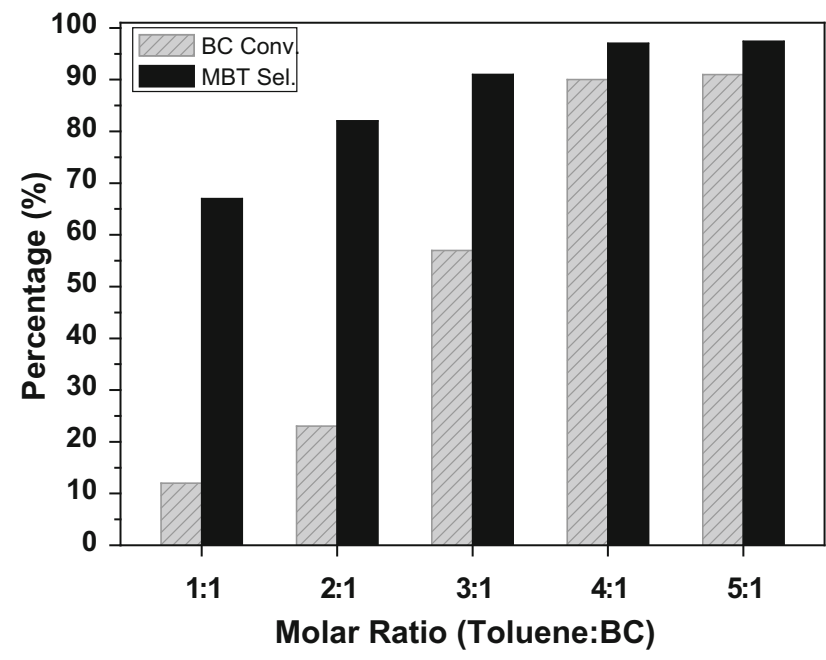

Fig. 4 Effect of molar ratio (toluene:BC) on toluene benzylation with BC over Hier-HZ-5 58 (reaction conditions: catalyst loading: $10 \%$, reaction temperature: $383 \mathrm{~K}$ and reaction time: $2 \mathrm{~h}$ )

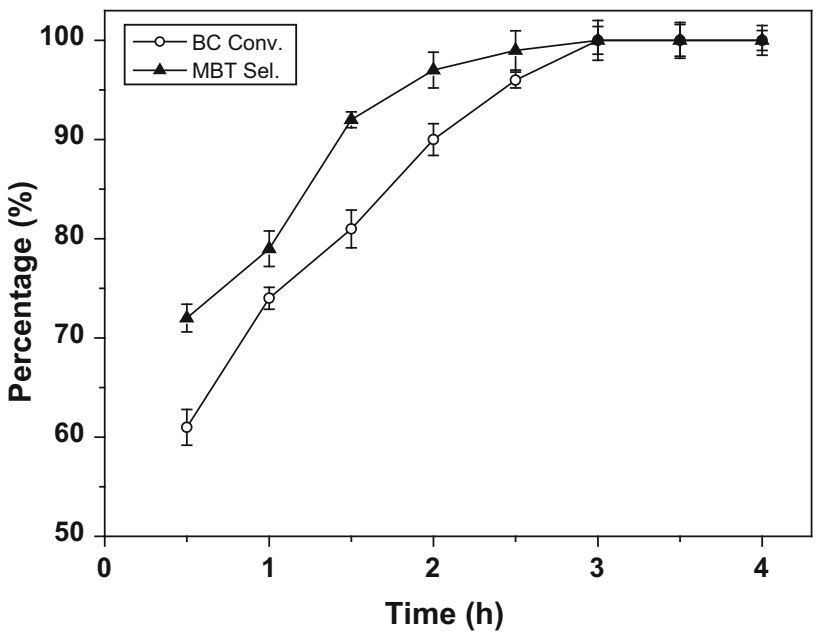

Fig. 5 Effect of reaction time on toluene benzylation with $\mathrm{BC}$ over Hier-HZ-578 (reaction conditions: molar ratio (toluene:BC) of 4:1, reaction temperature: $383 \mathrm{~K}$ and catalyst loading: $10 \%$ )

$(100 \%)$ and $100 \%$ MBT selectivity were obtained at reaction time of $3 \mathrm{~h}$. On further increase in reaction time up to $4 \mathrm{~h}$, the product distribution remained the same.

Effect of reaction temperature (373-393 K) was studied within reaction time of $0.5-4 \mathrm{~h}$ (Fig. 6). The results revealed that, with increases in reaction temperature from 373 to $393 \mathrm{~K}$ at fixed reaction time of $1.5 \mathrm{~h}$, the $\mathrm{BC}$ conversion increased from 65 to $84 \%$ and MBT selectivity from 75 to $85 \%$. However, the complete $\mathrm{BC}$ conversion $(100 \%)$ and $100 \%$ MBT selectivity can be obtained at reaction temperature of $383 \mathrm{~K}$ and above and at reaction time of $3 \mathrm{~h}$. Although, molar ratio of toluene to $\mathrm{BC}$ is relatively low (4:1), due to high temperature and high catalyst loading (active sites), the rate of forward reaction is higher than the backward reaction. Hence, the complete reaction with $100 \% \mathrm{BC}$ conversion and $100 \% \mathrm{MBT}$ selectivity is thermodynamically feasible. Thus, reaction time of $3 \mathrm{~h}$ and reaction temperature of $383 \mathrm{~K}$ were selected as optimum parameters.

\section{Catalyst reusability}

The reusability of Hier-HZ-578 catalyst was tested for benzylation of toluene with $\mathrm{BC}$ at optimized process parameters: molar ratio (toluene:BC) of 4:1, catalyst loading: $10 \%$ (wt. \% of $\mathrm{BC}$ ), reaction time: $3 \mathrm{~h}$ and reaction temperature: $383 \mathrm{~K}$. Hier-HZ-5 58 catalyst was found to be stable for six catalytic cycles (fresh and five reuses) with $100 \% \mathrm{BC}$ conversion and $100 \%$ MBT selectivity. After sixth cycle (for the seventh cycle) the marginal decrease in $\mathrm{BC}$ conversion from 100 to $97 \%$ and constant selectivity of $100 \%$ towards MBT was observed. After seventh cycle (fresh and six reuses) the spent catalyst was recovered by centrifugation and calcined in air at 


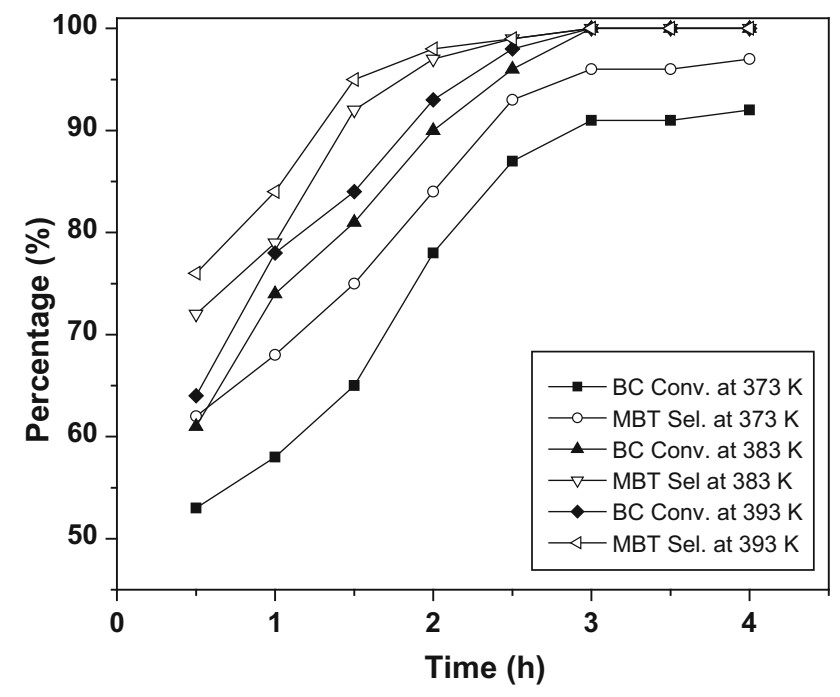

Fig. 6 Effect of reaction temperature on toluene benzylation with $\mathrm{BC}$ over Hier-HZ-5 $5_{78}$ (reaction conditions: catalyst loading: $10 \%$, molar ratio (toluene:BC) of $4: 1$ and reaction time: $0.5-4 \mathrm{~h}$ )

$823 \mathrm{~K}$ for $5 \mathrm{~h}$. Then the catalytic performance of this catalyst was tested in a new set of experiments for benzylation of toluene with $\mathrm{BC}$ under the identical reaction conditions. The catalyst was found to be active for the subsequent five cycles with an identical $\mathrm{BC}$ conversion of $100 \%$ and $100 \%$ MBT selectivity as in earlier set of experiments. This demonstrates that, Hier-HZ-5 $5_{78}$ catalyst is highly active and reusable with simple regeneration. Hence, use of Hier-HZ- $5_{78}$ catalyst for benzylation of toluene with $\mathrm{BC}$ would be an environmentally benign catalytic process with potential advantages with respect to high catalytic activity and simple catalyst regeneration.

\section{Merits of the present method}

The catalytic performances of all the catalysts developed in present study were evaluated for benzylation of toluene with $\mathrm{BC}$ at optimized process parameters and results obtained are summarized in Table 2. The catalysts exhibited the activity trend of Hier-HZ- $5_{78}(100 \%$ BC conv. and $100 \%$ MBT sel. $)>$ Hier-HZ-5 ${ }_{68}(81 \%$ BC conv. and $92 \%$ MBT sel.) $>$ Hier-HZ-5 $5_{90}(69 \%$ BC conv. and $87 \%$ MBT sel.). Benzylation of toluene with either benzyl alcohol or benzyl chloride (BC) has been extensively studied previously (Table 2). Vinu et al. [5] have reported alkylation of toluene with BC over AlSBA-15 catalyst with $31.2 \%$ BC conversion and $88.2 \%$ para-selectivity. A similar reaction catalyzed by Fe-SBA-15 afforded the corresponding para-alkylated product with $66 \%$ conversion and $100 \%$ selectivity [7]. Bokade and Yadav have used $30 \%$ TPA/TS- 1 catalyst for toluene benzylation with $\mathrm{BC}$ [6]. They obtained maximum $17.6 \% \mathrm{BC}$ conversion and $87.4 \%$ MBT selectivity. Very recently, toluene benzylation with $\mathrm{BC}$ was reported over Fe-containing HMCM68 and $\mathrm{STFe}_{3}$ catalysts, with $100 \%$ BC conversion and $100 \%$ MBT selectivity $[8,9]$. They have used high molar ratio (toluene: $\mathrm{BC}$ ) 10:1, which increases the cost of overall process [8,9]. Most of the reported [5-7] catalysts suffer from either lower BC conversion or MBT selectivity (Table 2). The present process of using Hier-HZ-5 78 catalyst for benzylation of toluene with $\mathrm{BC}$ offers a greener methodology with potential advantages with respect to complete reactant conversion (100\% BC conv.), $100 \%$ selectivity towards desired product (100\% MBT Sel.) and catalyst reusability for six cycles without loss in activity. The present study demonstrates principles of green chemistry such as easy separability and reusable catalyst, milder operating parameters and waste minimization.

\section{Conclusions}

The benzylation of toluene to mono-benzylated toluene (MBT) using benzyl chloride (BC) as benzylating agent

Table 2 Summary of the catalytic results obtained for the benzylation of toluene with benzyl chloride (BC) over the catalysts developed in present study and other catalysts reported in the literature

\begin{tabular}{|c|c|c|c|c|}
\hline Catalyst & Process parameters & $\mathrm{BC}$ conversion $(\%)$ & MBT selectivity (\%) & Reference \\
\hline AlSBA-15 & 3 wt. $\% ; 10: 1 ; 353 \mathrm{~K} ; 3 \mathrm{~h}$ & 31.2 & 88.2 & {$[5]$} \\
\hline $30 \%$ TPA/TS-1 & 6 wt. $\% ; 5: 1 ; 388 \mathrm{~K}: 2 \mathrm{~h}$ & 17.6 & 87.4 & {$[6]$} \\
\hline Fe-SBA-15 & 1 wt. $\% ; 7.5: 1 ; 353 \mathrm{~K} ; 75 \mathrm{~min}$ & 66 & 100 & [7] \\
\hline $\mathrm{STFe}_{3}$ & $0.1 \mathrm{~g} ; 10: 1 ; 373 \mathrm{~K} ; 20 \mathrm{~min}$ & 100 & 100 & [8] \\
\hline $\mathrm{FeCl}_{3} / \mathrm{HMCM}-68$ & 1 wt. $\% ; 10: 1 ; 383 \mathrm{~K} ; 2$ min & 100 & 100 & [9] \\
\hline Hier-HZ-590 & 10 wt. $\% ; 4: 1 ; 383 \mathrm{~K} ; 3 \mathrm{~h}$ & 69 & 87 & Present case \\
\hline Hier-HZ-5 78 & 10 wt. $\% ; 4: 1 ; 383 \mathrm{~K} ; 3 \mathrm{~h}$ & 100 & 100 & Present case \\
\hline Hier-HZ-568 & 10 wt. $\% ; 4: 1 ; 383 \mathrm{~K} ; 3 \mathrm{~h}$ & 81 & 92 & Present case \\
\hline
\end{tabular}

Process parameters are catalyst loading; molar ratio of toluene to $\mathrm{BC}$; reaction temperature; reaction time MBT mono-benzylated toluene 
was systematically studied. For the first time, modified zeolite (Hier-HZ-5 $5_{78}$ ) was used as a heterogeneous catalyst for toluene benzylation. Hier-HZ-5 58 catalyst has shown $100 \%$ conversion of $\mathrm{BC}$ and $100 \%$ selectivity towards MBT at optimum process parameters making the process environmentally benign. Catalytic activity Hier-HZ-5 was also found to be stable and reusable for six cycles (fresh and five reuses) without any loss in activity; hence it has industrial potential as it is benign. This study also revealed that less dilution of toluene to $\mathrm{BC}(4: 1)$ than reported $(10: 1)$ is enough to get complete conversion of $\mathrm{BC}$ and $100 \%$ selectivity of MBT.

Open Access This article is distributed under the terms of the Creative Commons Attribution License which permits any use, distribution, and reproduction in any medium, provided the original author(s) and the source are credited.

\section{References}

1. Olah GA (1973) Friedel-Crafts Chemistry. Wiley, New York

2. Singh AP, Bhattacharya D, Sharma S (1995) Benzoylation of toluene with benzoyl chloride over zeolite catalysts. J Mol Cat A Chem 102:139-145

3. Jin H, Ansari MB, Jeong EY, Park SE (2012) Effect of mesoporosity on selective benzylation of aromatics with benzyl alcohol over mesoporous ZSM-5. J Catal 291:55-62

4. Jana SK (2005) Recent developments of heterogeneous solid catalysts for liquid-phase Friedel-Crafts type benzylation reaction. Catal Surv Asia 9:25-34
5. Vinu A, Sawanat DP, Ariga K, Hartmann M, Halligudi SB (2005) Benzylation of benzene and other aromatics by benzyl chloride over mesoporous AlSBA-15 catalysts. Microporous Mesoporous Mater 80:195-203

6. Bokade VV, Yadav GD (2007) Synthesis of pharmaceutical intermediates by toluene benzylation over heteropoly acids on different support. J Nat Gas Chem 16:186

7. Anand C, Srinivasu P, Alam S, Balasubramanian VV, Sawant DP, Palanichamy M, Murugesan V, Vinu A (2008) Highly active three-dimensional cage type mesoporous ferrosilicate catalysts for the Friedel-Crafts alkylation. Microporous Mesoporous Mater 111:72-79

8. Devi KRPS, Sreeja PB, Sugunan S (2013) Environmentally benign Friedel-Crafts benzylation over nano- $\mathrm{TiO}_{2} / \mathrm{SO}_{4}{ }^{2-}$. Int Nano Lett 3:40

9. Li J, Xu C, Lou LL, Zhang C, Yu K, Qi B, Liu S, Wang Y (2013) Synthesis, characterization and catalytic properties of Fe-containing HMCM-68 for the benzylation of toluene. Catal Commun 38:59-62

10. Nandiwale KY, Niphadkar PS, Deshpande SS, Bokade VV (2014) Esterification of renewable levulinic acid to ethyl levulinate biodiesel catalyzed by highly active and reusable desilicated H-ZSM-5. J Chem Technol Biotechnol 89:1507-15015

11. Shiralkar VP, Joshi PN, Eapen MJ, Rao BS (1991) Synthesis of ZSM-5 with variable crystallite size and its influence on physiochemical properties. Zeolites 11:511

12. Nandiwale KY, Bokade VV (2014) Process optimization by response surface methodology and kinetic modeling for synthesis of methyl oleate biodiesel over $\mathrm{H}_{3} \mathrm{PW}_{12} \mathrm{O}_{40}$ anchored montmorillonite K10. Ind Eng Chem Res. doi:10.1021/ie500672v 